LA W REN CE LIVERM ORE NATIONAL LABORATORY

The 2D 'Shock-Jet' Problem

B. E. Morgan

May 31, 2013 
This document was prepared as an account of work sponsored by an agency of the United States government. Neither the United States government nor Lawrence Livermore National Security, LLC, nor any of their employees makes any warranty, expressed or implied, or assumes any legal liability or responsibility for the accuracy, completeness, or usefulness of any information, apparatus, product, or process disclosed, or represents that its use would not infringe privately owned rights. Reference herein to any specific commercial product, process, or service by trade name, trademark, manufacturer, or otherwise does not necessarily constitute or imply its endorsement, recommendation, or favoring by the United States government or Lawrence Livermore National Security, LLC. The views and opinions of authors expressed herein do not necessarily state or reflect those of the United States government or Lawrence Livermore National Security, LLC, and shall not be used for advertising or product endorsement purposes.

This work performed under the auspices of the U.S. Department of Energy by Lawrence Livermore National Laboratory under Contract DE-AC52-07NA27344. 


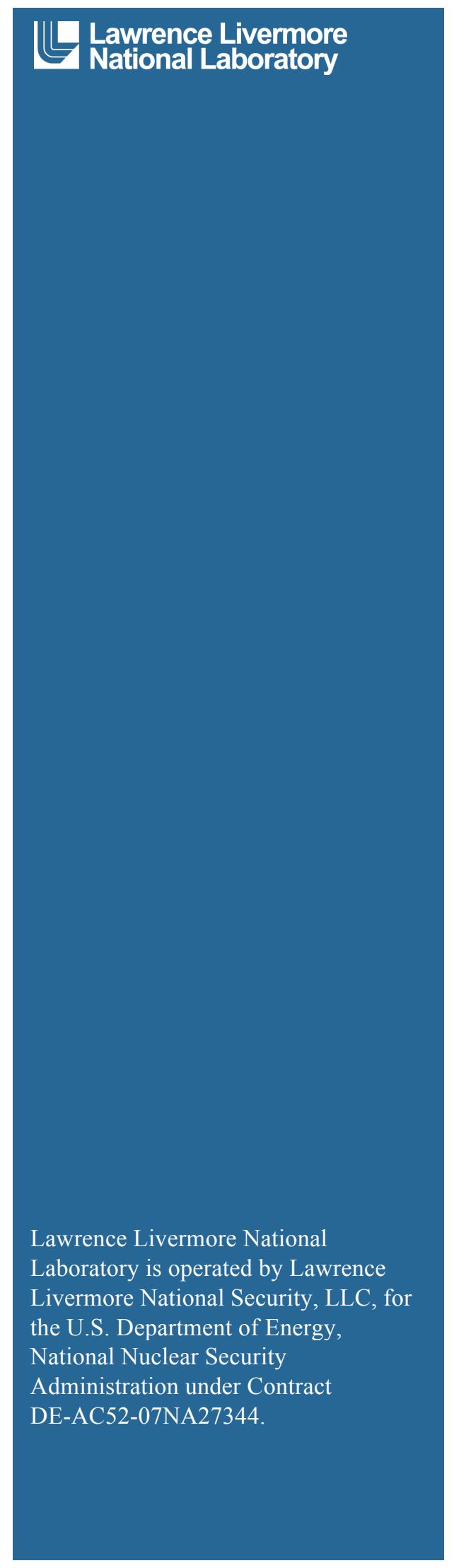

\section{The 2D 'Shock-Jet' Problem}

LLNL-TR-637828

Brandon Morgan

morgan65@llnl.gov

31 May 2013

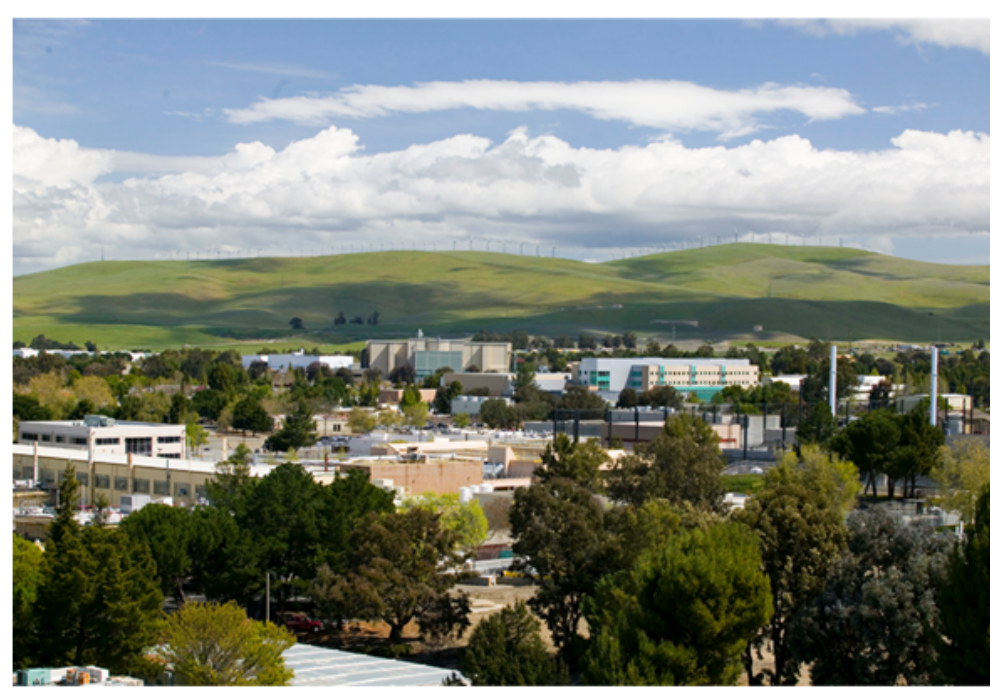




\section{Introduction}

Numerical simulation of Richtmyer-Meshkov instability (RMI) is conducted on a cylindrical interface between air and $\mathrm{SF}_{6}$ accelerated by a Mach 1.2 shock initially in air. Computational setup is intended to match conditions published by Shankar, Kawai, \& Lele [1] in their simulation of experimental work by Tomkins et al [2].

\section{Computational Domain}

The mesh is Cartesian and planar, parameterized by the diameter of the $\mathrm{SF}_{6}$ cylinder $(\mathrm{D}=0.6 \mathrm{~cm})$. The center of the cylinder is located at the origin, and the mesh extends from -17D to 38D in the streamwise (x) dimension and from $-12.5 \mathrm{D}$ to $12.5 \mathrm{D}$ in the stream-normal (y) dimension, as illustrated in figure 1 .

Note: If non-reflecting boundary conditions are not available, these dimensions will need to be increased to prevent reflected waves from affecting the cylinder. Grid spacing should be defined by the number of zones across one cylinder diameter. Suggested values: 82, 245, and 736 zones/cylinder. Use of adaptive mesh refinement (AMR) is recommended to localize zones around the cylinder and shock interface.

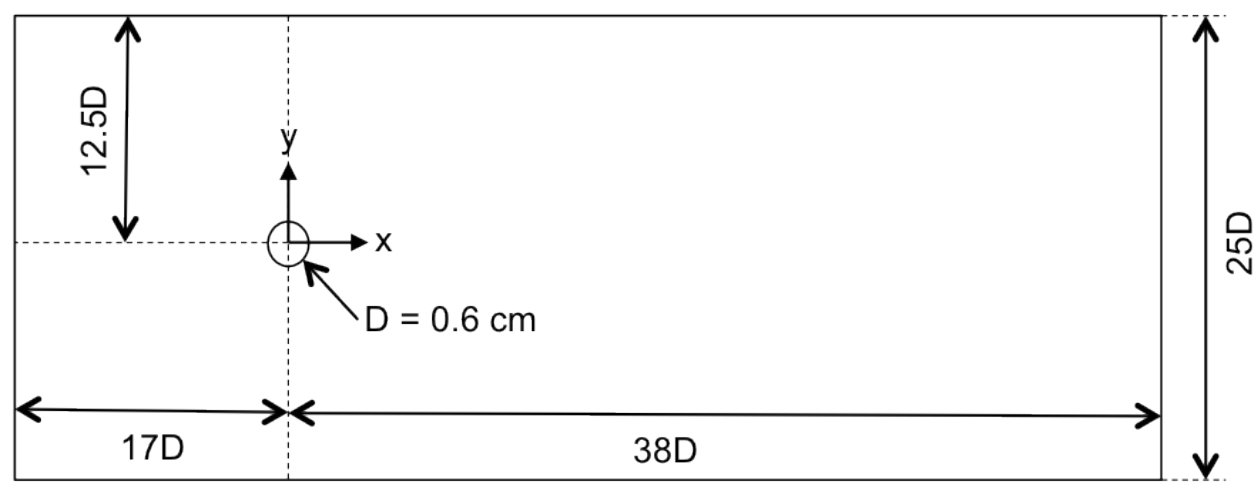

Figure 1. Computational domain (not to scale).

\section{Initial Conditions}

The problem is solved in a laboratory fixed coordinate frame such that the shock, initially located at $\mathrm{x}=$ $1.5 \mathrm{D}$, is observed to propagate from left to right at a speed of Mach 1.21. Initial pressure and temperature in the stationary unshocked gas (right of the shock wave) are 0.8atm and $298 \mathrm{~K}$, respectively. Initial velocity and thermodynamic conditions in the shocked gas (left of the shock wave) are given by the Rankine-Hugoniot jump conditions. Air is assumed to be a mixture of $79 \% \mathrm{~N}_{2}$ and $21 \% \mathrm{O}_{2}$ (by molar ratio). Initial mass fraction of $\mathrm{SF}_{6}$ within the cylinder is given as a function of radial distance, $r$, from the origin where $Y_{\max }^{0}=0.83$.

$$
Y_{S F_{6}}^{0}(r)=\left\{\begin{array}{cc}
Y_{\max }^{0}\left(1.0-\exp \left(\frac{-\|\left.\left(\frac{|r|}{D / 2}-1\right) \pi\right|^{1.54}}{1.0082}\right)\right) & |r| \leq \frac{D}{2} \\
0.0 & |r|>\frac{D}{2}
\end{array}\right.
$$




\section{Equations of State}

Thermodynamic variables in both air and $\mathrm{SF}_{6}$ are assumed to be governed by the ideal gas equation of state, with the ratio of specific heats $(\gamma)$ equal to 1.40 for air and 1.09 for $\mathrm{SF}_{6}$.

\section{Boundary Conditions}

Inflow conditions should fix velocity and thermodynamic conditions in the shocked gas. Outflow conditions should fix the gas velocity, with special care taken not to reflect the principal shock wave. North and south boundaries should be non-reflecting "sponge" boundaries to allow perturbations in velocity and thermodynamic variables to go smoothly to zero. If non-reflecting boundary conditions are not available, the computational mesh will need to be extended in both the streamwise and stream-normal dimensions to prevent reflection of the primary shock and secondary acoustics from interacting with the cylinder.

\section{Temporal Evolution}

The problem is initialized at time $t=0$ and run out to $t=1000 \mu \mathrm{s}$.

\section{Diagnostics}

The following data are suggested for comparison:

1. 2D fields of $\mathrm{SF}_{6}$ concentration (mass fraction) in pseudo-color at times $t=130,220,310,400$, 490, 560, 650, 760, 880, and $1000 \mu s$.

2. 1D plots of total mixing rate (TMR) versus time.

3. 1D plots of enstrophy $(\Omega)$ versus time.

TMR is an integral measure of the instantaneous scalar dissipation rate (or mixing rate), defined below, where $D_{S F_{6}}^{m o l}$ and $D_{S F_{6}}^{t u r b}$ represent, respectively, the molecular and turbulent coefficients of diffusivity for $\mathrm{SF}_{6}$ into air.

$$
T M R=\iint\left(D_{S F_{6}}^{m o l}+D_{S F_{6}}^{t u r b}\right) \nabla Y_{S F_{6}} \cdot \nabla Y_{S F_{6}} d x d y
$$

For the Tipton K-L model, $D_{S F_{6}}^{\text {turb }}=\mu_{t} /(\rho \mathrm{Sc})$. If molecular viscosity and diffusion are computed, $D_{S F_{6}}^{\text {mol }}$ is given by the Chapman-Enskog method [1]. Otherwise, $D_{S F_{6}}^{m o l}=0$.

Enstrophy is an integral measure of total vorticity, defined below as the integral of the square of vorticity.

$$
\Omega=\iint \omega_{z}^{2} d x d y
$$

\section{References}

[1] Shankar, S.K., Kawai, S., and Lele, S.K. "Two-dimensional viscous flow simulation of a shock accelerated heavy gas cylinder," Physics of Fluids, 23(2), 2011.

[2] Tomkins, C., Kumar, S., Orlicz, G., and Prestridge, K. "An experimental investigation of mixing mechanisms in shock-accelerated flow," Journal of Fluid Mechanics, 611:131-150, May 2008. 


\section{Disclaimer}

This document was prepared as an account of work sponsored by an agency of the United States government. Neither the United States government nor Lawrence Livermore National Security, LLC, nor any of their employees makes any warranty, expressed or implied, or assumes any legal liability or responsibility for the accuracy, completeness, or usefulness of any information, apparatus, product, or process disclosed, or represents that its use would not infringe privately owned rights. Reference herein to any specific commercial product, process, or service by trade name, trademark, manufacturer, or otherwise does not necessarily constitute or imply its endorsement, recommendation, or favoring by the United States government or Lawrence Livermore National Security, LLC. The views and opinions of authors expressed herein do not necessarily state or reflect those of the United States government or Lawrence Livermore National Security, LLC, and shall not be used for advertising or product endorsement purposes. 